\title{
Apple Fruit as a Source of Health Beneficial Compounds
}

\author{
Sabaz AK* \\ Department of Biotechnology, COMSAT University Islamabad, Abbottabad Campus, \\ 22060, Abbottabad, Pakistan \\ *Corresponding author: Sabaz AK, Assistant Professor Biotechnology Program, \\ Editorial \\ Volume 2 Issue 1 \\ Received Date: May 22, 2019 \\ Published Date: June 26, 2019 \\ DOI: $10.23880 /$ aabsc- 16000129 \\ Department of Environmental Sciences COMSATS Institute of Information Technology, Abbottabad, Pakistan, Tel: \\ 03049753542; Email: sabzktk@yahoo.com
}

\section{Editorial}

Fruits are well known for their high value in human health. Epidemiological studies indicate that consumption of fruits, vegetables and their products are inversely related to carcinogenesis, coronary heart disease, mortality, and aging processes [1]. It has been suggested that this reduction is not only due to increased levels of vitamins and fibers, but that other compounds, such as phenolic compounds, also appear to play an important role in the overall antioxidant capacity of fruits and vegetables [1]. It is clear from the fact that there has been recorded a substantial increase in heart and vascular diseases, obesity, cancer and also diabetes due to less fruit intake in food [2]. The antioxidant properties of phenolic compounds present in plant food may contribute to these health beneficial effects [3]. These secondary metabolites, which occur abundantly in plant foods, have been discovered to be beneficial components of functional food [4]. Their positive effects on human health were first proposed by Bentsáth (1936) [5] and are now widely accepted. Plant phenolic compounds are well recognized for their antioxidative activities and apple is well known for its high levels of these compounds. They scavenge free radicals, thus breaking the free radical chain reaction of lipid peroxidation [6]. "An apple a day keeps the doctor away". This saying has encouraged many researchers to search for the "magic" ingredients of apple. Apple possesses many health beneficial properties for human being as a rich source of phenolic compounds. Cultivated apple is one of the most important cultivated fruit species. It belongs to the family Rosaceae and sub-family Maloideae that includes many commercial fruit species such as pear, strawberry, cherry, peach, apricot, almond and black cherry [7]. It is the main fruit crop of temperate regions of the world and is produced commercially in 91 countries with a total production of 64 million tons. It has been associated with lowering the risks of cancers, particularly prostate, liver, colon, and lung cancers cardiovascular diseases, coronary heart diseases, asthma, type-2 diabetes, thrombotic stroke, and ischemic heart disease [8-10].

Phenolic compounds are an important part of the human diet and have great importance in the nutritional and commercial properties of agricultural foodstuffs. Phenolic compounds comprise one of the largest and most ubiquitous groups of plant metabolites. Some of the major phenolic compounds isolated and identified from apple are chlorogenic acid, hydroxycinnamic acid, epicatechin, catechin, gallaocatechin, procyanidins, phloretin-glucosides, quercetin glycosides, and dihydrochalcone glycosides [4]. The most commonly occurring ones in foods are flavonoids and phenolic acids. The diversity of the chemical structures and variability in foods make calculation of the phenolic content difficult. For example, the average intake of flavonols and flavones was estimated as $23 \mathrm{mg} /$ day [6]. Phenolic content of plant food is currently considered a measure of product quality [6]. The content of phenolic compounds varies in different plant species and even from tissue to tissue within the same plant species. For instance, Lata, [11] measured the average phenolic content in 53 different apple cultivars in two successive growing years 2003 and 2004. The average phenolic content for different cultivars was 777$1842 \mathrm{ug} / \mathrm{g}$ in year 2003 and 476-2349 ug/g in 2004. In another study by Lata, [12] phenolics for whole fruit was found to be $1600-4600 \mathrm{ug} / \mathrm{g}$. They found that the total phenolics in peel were three times higher than in flesh [12]. Van der Sluis, et al. [13] also found that flavonoids 
are not equally distributed throughout the apple. For instance, quercetin glycosides are almost exclusively found in peel and have very low concentration in flesh. Phloridzin was found both in peel and flesh. Mcghie et al. [10] found on average $46 \%$ of the phenolic compounds of apple in the peel and determined that flavanols contents were higher in flesh than in peel. Like Van der Sluis, et al. [13], Mcghie, et al. [10] also observed that phloridzin was present both in peel and flesh as well as procyanidins. Chlorogenic acid was more in flesh $(80-85 \%)$ whereas anthocyanins only were determined $(100 \%)$ in peel [10]. The knowledge of these beneficial phenolic compounds in apple could incline the consumer for more fruit consumption because of improved health values.

\section{References}

1. Sanchez RF, Jauregui O, Lamuela-Raventos RM, Viladomat F, Bastida J, et al. (2004) Qualitative analysis of phenolic compounds in apple pomace using liquid chromatography coupled to mass spectrometry in tandem mode. Rapid Communications in Mass Spectrometry 18(5): 553563.

2. Hollman PCH, Katan MB (1999) Dietary flavonoids: Intake, health effects and bioavailability. Food and Chemical Toxicology 37(9-10): 937-942.

3. Kaur C, Kapoor HC (2001) Antioxidants in fruits and vegetables - The millennium's health. International Journal of Food Science and Technology 36(7): 703725.

4. Treutter D (2001) Biosynthesis of phenolic compounds and its regulation in apple. Plant Growth Regulation 34(1): 71-89.

5. Bentsáth A, Rusznyák S, Szent-Györgyi A (1936) Vitamin nature of flavones. Nature 138: 798.
6. Hertog MGL, Hollman PCH, Katan MB, Kromhout D (1993) Intake of potentially anticarcinogenic flavonoids and their determinants in adults in The Netherlands. Nutrition and Cancer 20(1): 21-29.

7. Park S, Sugimoto N, Larson MD, Beaudry R, Van Nocker S (2006) Identification of genes with potential roles in apple fruit development and biochemistry through large-scale statistical analysis of expressed sequence tags. Plant Physiology 141(3): 811-824.

8. Xing N, Chen Y, Mitchell SH, Young CYF (2001) Quercetin inhibits the expression and function of the androgen receptor in LNCaP prostate cancer cells. Carcinogenesis 22(3): 409-414.

9. Hyson D, Studebaker-Hallman D, Davis PA, Gershwin ME (2000) Apple juice consumption reduces plasma low-density lipoprotein oxidation in healthy men and women. Journal of Medicinal Food 3(4): 159-166.

10. Mcghie TK, Hunt M, Barnett LE (2005) Cultivar and growing region determine the antioxidant polyphenolic concentration and composition of apples grown in New Zealand. Journal of Agricultural and Food Chemistry 53(8): 3065-3070.

11. Lata B, Przeradzka M, Bínkowska M (2005) Great differences in antioxidant properties exist between 56 apple cultivars and vegetation seasons. Journal of Agricultural and Food Chemistry 53(23): 8970-8978.

12. Lata B (2007) Relationship between apple peel and the whole fruit antioxidant content: Year and cultivar variation. Journal of Agricultural and Food Chemistry 55(3): 663-671.

13. Van der Sluis AA, Dekker M, De Jager A, Jongen WMF (2001) Activity and concentration of polyphenolic antioxidants in apple: Effect of cultivar, harvest year, and storage conditions. Journal of Agricultural and Food Chemistry 49(8): 3606-3613. 